\title{
(Israeli) The Evolution of Teacher Trainees' Perceptions about the Linkage between the Terms Moral Resilience and Moral Courage through the training process
}

\author{
Baratz lea (Corresponding Author) \\ Achva Academic College of Education, D.N. Shikmim, Israel \\ E-mail: 1baratz@netvision.net.il
}

Received: January 16, 2017

doi:10.5296/jet.v4i2.10608
Accepted: March 30, $2017 \quad$ Published: July 28, 2017

URL: http://dx.doi.org/10.5296/jet.v4i2.10608

\begin{abstract}
The perceptions of 123 (11 men and 112 women) teacher-trainees regarding the characteristics of moral resilience and moral courage and the linkage between the two were explored using an online questionnaire designed especially for this study. Four themes emerged from the content analysis. (a) The concepts were perceived as embedded in a comprehensive framework encompassing a multifaceted society. (b) Specific factors contribute to the development of moral fiber, which is viewed as the core of resilience. (c) Three linkage patterns were identified between moral resilience and moral courage. (d) The terms were perceived as buzzwords. A clear conceptualization of the notion of moral resilience could facilitate the construction of a process-building model for developing individuals' resilience (the micro level). Thus, teachers with moral resilience would serve as role models in the schools (the meso level), which could then lead to building community-wide resilience (macro-level).
\end{abstract}

Keywords: Moral courage, Moral Resileance, Teacher Trainees

\section{Introduction}

The perception of Teacher Trainees' as moral agents is because through their spoken articulation, actions, and teaching methods they are constantly educating and communicating about values in general, and about moral values in particular. Moral education is at the heart of education and, hence, it should be a focal point in teacher education. However, it was found that the issue of morality as part of the educational process has disappeared from the professional discourse and culture of teaching and teachers (Buzaglow, 2010). Locally and globally, it appears that any direct or overt dealing with morality is perceived as an exceptionally challenging issue for teachers, who do not feel qualified to handle discussions on morality or to conduct informed moral debates with their students. There are many reasons for this state of affairs, yet it seems that the lack of awareness towards this issue in the 
teacher training process causes teachers to avoid coping with moral issues in the context of education, and to sidestep the issue of moral education altogether. Therefore, it seems appropriate to introduce the terms moral courage and moral resistance into the teacher training process, as an integral part of teacher education.

\subsection{The Context of the Study}

Value-related issues, such as friendship, honesty, justice, and courage, were debated already in Aristotle's days. Aristotle used the term measure to refer to the action related to morality, i.e., the action that follows after a person has given rational thought to the extreme actions that could be taken and chooses "the golden mean". This "measure" expresses the individual's ability to weigh the various possibilities and to make an optimal choice in a given situation. Choosing the golden mean enables one to acquire "good measures" and to become a moral human being. A good human being is one who activates his or her mental powers in order to choose among many different options and actions. Morality, according to Aristotle, is acquired through action, which leads one to adopt moral behaviors. Hence, choosing the golden mean is tantamount to making a moral choice.

In effect, constructing moral character, according to Aristotle, is based on the "ethics of good measures" that is, it involves the acquisition and adoption of certain personal characteristics, accompanied by rational consideration, leading to the selection and performance of the golden mean, and finally, a committed decision to act according to said choice (Aristotle, 1962). Aristotle's concept of morality is complemented by the development of the concept of resilience.

In recent years, there has been rapid development in the research on resilience (Herrman et al., 2011), yet no single comprehensive definition has been found. Noticeably, attempts to define resilience have relied on various disciplines, such as psychology, sociology and, recently, the field of genetics. Most of the definitions consider the sources of resilience to be associated with the personal, biological, and environmental aspects or a combination of all or part of these factors, and they rely on associated terms such as mental resilience, communal resilience, and national-social resilience. The current study examined the degree to which teacher trainees are aware of the concept of moral resilience in the context of teaching.

Although the concept of resilience has been widely used by the media in a variety of contexts, it has yet to be defined in an educational context. In the sphere of the community, a great deal of attention is focused on resilience, because it is understood that resilience plays a significant role in the process of establishing a functioning, efficient, and respectable society. As the school is the default organizational framework, its mission, organizational climate, and manner of coping must remain stable, especially when facing change. Thus, a clear conceptualization of the notion of resilience could provide guidelines for constructing a resilience-building process for the benefit of the individual. Undertaking this process within the framework of a broader system, such as the school unit (the meso level), lays the foundation for creating (macro-level) community resilience.

The issue of moral resilience has yet to be investigated among teacher trainees, either in 
Israel or in elsewhere. Therefore, based on the findings of the current study, I will suggest instruments that ought to be implemented in teacher-training programs that wish to address the issue of moral resilience. Teacher trainees constitute an important component of any social structure; hence, their perceptions merit investigation.

\subsection{Theoretical Background}

In this section, the two core terms, moral courage and moral resilience, are introduced.

\subsubsection{Moral courage and Moral Courage of Teachers}

Facing ethical issues often obliges us to take an action that entails inconvenience (author, 2013), harm, or danger. Such actions require "moral courage" (Duska, 2013). Rorty (1988) puts the issue sharply into focus and explains the need to re-conceptualize courage. She addresses courage as part of her attempt to understand various human virtues, and differentiates between the traditional definition of courage and a new definition of courage. In her view, the traditional conceptualization of courage raises various problems concerning its very definition as a virtue, hence the need to re-examine the question, "What is courage?" The traditional definition of courage as a set of dispositions that enable us to overcome fears related to potential obstacles and to perform difficult and dangerous actions does not present courage as a virtue, although it is valued as an important quality for survival purposes.

According to some definitions, moral courage is the ability of individuals to overcome fear and stand up for their main values and ethical commitments (Lachman, 2007), or as Kidder formulates it, "moral courage is the courage to be moral" (Kidder, 2005, p. 10). According to Kidder (2005), moral courage includes three main elements: danger, principles, and endurance, and it can be identified by five basic qualities: integrity, honor, responsibility, decency, and compassion. Thus, moral courage is the bridge between talking about values and actually implementing them.

Miller (2000) defines moral courage as the willingness to take a stand in defense of principles or convictions even when others do not. People who exhibit moral courage are often subject to a number of risks associated with taking a stand, including inconvenience, unpopularity, ostracism, disapproval, derision, and even harm to themselves or their relatives. Aultman (2008) concludes that discourse with colleagues about experiences relating to ethical dilemmas is an important starting point from which to find solutions to such dilemmas. Discourse among professionals from the same field, but from different locations (such as physicians working in rural and urban areas) can promote an understanding of political, emotional, and ethical factors, "and by that intensify moral courage and ethical activity" ( $p$. $67)$.

In a teaching context, moral courage means the willingness to protect our values publicly. To awaken their students' awareness, teachers must have the desire and the ability to discuss ethical issues (Klaassen, 2007, Klaassen, 2012). They cannot be content with merely teaching compulsory knowledge or even with promoting thinking skills (Klaassen \& Maslovaty, 2010). Moral courage among teachers is characterized by a mental challenge: individuals who take a stance could risk damaging their reputation, their emotional world, or self-image. An act of 
moral courage is connected to the most central values of the person who takes a moral stance (Kidder, 2005; Klaassen \& Maslovaty, 2010). Some teachers maintain that the task of moral education is a central element in their role as educators and view themselves as agents of critical education and as persons who show great moral courage (Kidder, 2005). Thus, the very understanding of the teachers that moral education is a central aspect of their work is in itself an expression of moral courage (Klaassen \& Maslovaty, 2010).

Conflicts should be placed at the heart of the curriculum that is built upon values of a strong and open democracy, knowing that winning is not the issue. It is very important to involve students in such discussions, to present them with contrasting opinions and to cause them to take a stance. This involvement serves to expose students to the issues that adult's debate, enabling them to understand why these issues are so important and to locate their own opinions on the continuum of those presented. "A true democratic education is based on an exchange of ideas and understanding that denial of the other becomes an anti-democratic act " (Graff, 1994, p. 10). Graff claims that, paradoxically, what divides us now can unite us and can serve nonacademic and pre-academic education as an organizing and uniting factor. Furthermore, he notes that although some teachers are involved in debates concerning what should be taught and how it should be taught, they still refrain from including students in these disputations, thereby preventing an essential democratic dialogue from taking place.

The issue of moral courage of teachers in the Israeli education system is of special significance, because the Israeli Ministry of Education has complete and centralized control in determining educational policy and activities for all schools in the country (author, 2010). Therefore, the Ministry of Education has subsequently encouraged conformist behavior of teachers in alignment with these policies throughout the years of the existence of the State of Israel (2013). Michaeli (2014) notes that the attempt to prohibit teachers from engaging in political matters in the classroom is in effect nullified by an awareness of the political aspects implicit in the curriculum. Hence, it is impossible to "extract" political issues from the realm of education, and instead, a more worthy discussion ought to focus on how political issues should be introduced and handled (p. 21).

\subsubsection{Resilience and Moral Resilience.}

According to the American Psychological Association (APA, 2009), mental resilience is not a characteristic with which one is born, but rather a combination of thoughts, behavior's, and activities, that can be learned by the individual. The APA (2009) proposes ten strategies for building mental resilience: developing positive relationships, taking a different view of unsolved problems, accepting change as part of life, setting goals and pursuing them, acting with determination, seeking opportunities for self-discovery, believing in one's abilities, viewing things in perspective, maintaining hope, practicing self-preservation, and seeking additional ways to build personal resilience. Mental resilience is defined as one's ability to cope with difficulty, e.g., a period of continuous stress, and to emerge strengthened and with new insights, as well as the ability to return to the previous condition (Killian, 2004, Bleich, 2007 ), and the ability to recover and adjust to change (Berggren, 2006). Ogman (2012) notes that the process of resilience building is an individual matter that combines elements derived 
from biology, the environment, and learning. Taplin (2011) suggested and demonstrated four main components that constitute mental resilience, the most prominent of which is based on organic components, such as beliefs, values, and skills, which are derived from the individual's personality and manifested in the individual's thoughts and behaviors. Next in order of importance, according to Taplin, is the factor combining family, school, and the surrounding community, followed by society in general. Even though most teachers believe that, it is important to help students to develop, personal attributes such as resilience (Mansfield, Beltman, Price, \& McConney, 2012). Then they can cope with the challenges and changes of contemporary society, teachers and students are too often caught up with the demands of the curriculum and the stress of exams to be able to attend to the development of personal values. Consequently, we need to find a way to help teachers address this need without hindering their ability to meet curricular requirements and foster high-level academic achievements (Taplin, 2011). To the personal factor and Communal resilience one should add the National-social resilience, which forms part of a nation's strength (or weakness) and relates to the psychosocial characteristics as well as to the public's capacity for adjustment in a given period. This is manifested in the degree of commitment of the individuals in a society to act to uphold common interests, while maintaining the rights of all individuals, as well as their own ability to cope with various types of hardships (Gal, 2003: Peled 2004).

\subsubsection{Moral resilience.}

Moral resilience relates to the ability (of an individual or a group) to remain steadfast in one's convictions when these are challenged. Thus, for example, a morally challenging situation might call into question certain fundamental values that inform people's behaviors, whether as individuals or as a group. Similarly, a morally challenging situation is one in which people might find themselves prone to think or behave in ways that either cast doubt on, risk undermining, or even lead them to completely reject the validity of their own fundamental values (Ofer, Rix \& Harel, 2008). Consequently, it may be said that moral resilience comes to the forefront in situations that question pre-existing and accepted conventions, the beliefs that define one's (or a group's) understanding of what is right and wrong, appropriate and inappropriate. Moral resilience is manifested when there is a sense of commitment and the willingness to act according to these convictions. Often, a major component of moral resilience is a feeling of communality and solidarity, which may lead one to assume responsibility and look after those who are under one's care.

Ediger (2013) defines a resilient person as one who tends to learn from unpleasant efforts and modifies behaviour to ensure future success. Failure tends to be a learning experience: deficiencies are evaluated and new procedures are created and then evaluated, in an effort to be more successful in the subsequent endeavour. Thus, the resilient person makes choices in life, some of which may involve choosing from among several good options, while other times, unfortunately, the choices to be made are between the lesser of two evils.

"There is no need to teach values - nor is it possible." (Yizhar,1990, p. 116) His opinion is based on a perspective, according to which modern society does not inculcate values, but rather nurtures individuals to be able to select the moral principles that they find suitable and 
worthy, according to the varying situations and roles. In 2013, the Ministry of Education presented a document that discussed the need to educate students in Israel about moral values (Barandes and Isaschar, 2013). The document encompassed a wide range of questions on this issue, such as, 'are there moral principles which are "absolute"?' 'Do morals depend on a particular educational theory?' The teaching of moral principles is affected by particular worldviews and by the interests of social groups that aim to influence the educational process in general, and the process of educating for values, in particular. Such groups include parents, politicians, employers, or ideological sects in society. Ethical or moral conflicts and debates are an integral part of any society. There is a wide range of definitions for the term moral value. 'Morals are standards we use to consider what is right and what is wrong, the principles on which we base our judgment of people, objects, ideas, actions, and conditions. By applying this standard, we determine whether these are "good and worthy" or, conversely, "bad and contemptible"" (Schechter \& Iram, 2002, p. 11).

\subsubsection{Moral resilience of teachers.}

Gu and Day (2013) examined ways in which teachers could be resilient, as they considered resilience a prerequisite to the ability to teach well and to do so over an extended period of time. There had been a paucity of prior research on "the ways in which [resilience] may be nurtured, sustained or eroded over time". According to their view, resilience is affected not only by one's personal biography, but also by factors related to one's socioeconomic conditions, culture, the educational policies, personal circumstances, and work conditions. The main concern of these authors was to answer the following question: "under what conditions do teachers choose to retire?" Their conclusion was that resilient teachers continue to teach, in contrast to teachers who explain their decision to resign by referring to various difficulties, for example, "coping with student-generated noise levels." The important addition made by these authors regarding the definition of resilience is about not only the ability to overcome a traumatic experience that takes place in the context of teaching, but also mainly the ability to maintain a balance and a sense of commitment and dedication, particularly in the milieu that teachers encounter in their daily work. Accordingly, resilience in teachers is the ability to manage the uncertainty that is inevitable in the reality of the world of education. Edwards (2011) adds that teachers' resilience is motivated by their educational goals and their moral values, although these do erode in the course of the individual's interface with typical workaday procedures. As noted, resilience is affected by the teachers' personal biography, and life and work circumstances. The moral resilience of a school team can be attributed to a strong cultural-organizational core. The framework that defines the mutual expectations and the behavioral patterns used in various situations, and it attributes significance to particular events. It is what guides decision-making (Gu \& Day, 2013).

The contribution of the current study is in examining the perceptions of teachers-in-training regarding the concept of moral resilience, in order to raise consciousness of this concept, and to incorporate it in the training process. 


\section{Methodology}

\subsection{The Goal of the Study}

The goal of the study is to examine teacher trainees' perceptions of the notion of moral resilience and linkage between this term and moral courage, a term they learned during their studies, and to understand the ways in which they conceptualize it.

\subsection{Participant}

A total of 123 participants (11 men and 112 women) completed the questionnaire; Participants' age distribution was as follows: 58 of the respondents were between the ages of 20 and 30; 32 of the respondents were between the ages of 30 and 40; and 16 respondents were 40 years of age or older. The reason for selecting this population was that on the one hand, its members are the product of an educational system that attempted to form them into who they are, and on the other hand, they chose to become those who would help form the next generation.

The study was conducted in a college, attended by Israeli students. The study participants were at least in their second year --or more advanced-- in the latter programme, preparing to teach in the system in which the Ministry of Education dictates the core curriculum and the educational focus. Participants were preparing to become teachers in one of the following fields: sciences, special education, or humanities. The number of students was selected to serve as a representative sample of the student body at the college.

\subsection{Research Tools}

A study questionnaire designed especially for the current study was distributed online among trainees in a teacher-training. Given that the questionnaire was administered online, students were free to opt-in or ignore it. Those who chose to complete the questionnaire were able to upload it anonymously. The questionnaire included demographic details as well as open-ended questions regarding the essence of the concept of moral resilience. The students were asked to define what they considered to be the foundational components of the concept of moral resilience and if there is a linkage between moral courage and moral resilience.

The use of open questions designed to allow extensive verbalization non biased. Respondents were asked to describe their experience about the sense of moral resilience or moral courage and to tell about their feelings following the experiences. In addition, to characterize components of the concept and to try, provide a definition to those terms.

Two experts in the field of education validated the questionnaire. Furthermore, the current questionnaire is based on the assumption that in the course of training in a particular field, students identify the factors that are likely to shape the development of their professional and personal identities. 
The questionnaire consists of open-ended questions, presented in a systematic order (Spradley, 1979). Questions begin with a broad and general inquiry about moral resilience, followed by questions that relate to local situations and incidents and requests for examples. The final question asks about actual personal experience.

\subsection{Data Analysis}

Analysis of the statements was conducted inductively (Goetz, \& Le Compt, 1984), a method in which the researcher attempts to identify repeating patterns within the collected data. A didactic, interpretational-qualitative approach was employed, based on the critical analysis of statements and the use of 'semantic fields' (Sovran, 2013). Accordingly, the investigator uses an interpretive approach to identify and mark the relevant statements. Analysis was conducted in a cyclical manner (Guba \& Lincoln, 1989), with assistance from an additional professional in the field of education. Analysis of the statements was conducted in three stages: discovery, examination, and conclusion drawing (Weber, 1985). The research relied on the interpretive approach to identify and outline components within the answers that were relevant to moral resilience; these components were emphasized and colour-coded to represent various conceptual categories. The researchers highlighted in the category anything connected with Personality Components and Immunity, and as more categories emerged, they repeatedly went back to the answers of the students to find proof (in the form of segments of authentic text) that supported the categories they had formulated and the keywords they identified (Katriel, 1999).

In the first stage, comments were entered on the margins of the text regarding anything that caught the readers' attention and seemed relevant. The second stage included grouping the verbal content, in order to identify meaningful units in the text, units that were deemed representative of ideational meanings. This interpretive process led to the sorting of meaningful units into grounded categories, which could be used to discern additional meanings in the sections that remained. In the third stage, a new array of meaningful factors was constructed, by establishing the existence of recurring connections and relationships between units of meaning, identified via repetition of statements in the data. These statements converged to create a common perception with similar features, a perception which the participating trainees evidently shared, and which was constructed using the method of axial coding. Thus, a hierarchical system of categories was devised, by incorporating thematically similar categories (subcategories) within broader categories.

\subsection{Ethics in Research}

Throughout the research, emphasis on the rights of the participants was meticulously observed, for upholding professional ethical standards, and to avoid invading the privacy of the individual participants. The purpose of the research and the framework in which it would be carried out was made clear to the participants, as well as the fact that their participation in the research was voluntary. 


\section{Findings}

Three major themes emerged in trainees' conceptualizations of the notion of moral resilience and moral courage: (1) The Social-Educational Framework as a Protective Environment (2) The linkage between the two terms -- moral resilience and moral courage; (3) the terms as buzzwords.

\section{Theme 1: The Social-Educational Framework as a Protective Environment}

In participants' discussion of the notions of moral resilience and moral courage, the concepts were clearly viewed as embedded in a comprehensive framework, within which the individual is seen as an integral part of a multifaceted society, and the process of establishing resilience or moral courage is intended to empower the individual. The framework ensures that trainees' actions correspond to clearly defined codes, which include the development of an individual and a group identity, as well as the development of a personal worldview. However, the teacher trainees expressed the belief that only once they are professionally established, and they are able to exert their personal influence on the framework will they feel that they can afford to demonstrate moral resilience. Adherence to moral values is a conscious desire to belong to a community, whereby a shared awareness dictates the actions. Characteristics such as flexibility and adaptability were emphasized, with an understanding that these would be helpful in times of crisis, and particularly in order to endure crisis. Mental flexibility leads to the ability to adapt to and withstand changes, and in turn, this ability to contain one despite changes gives rise to moral resilience and the ability to withstand crises.

The following statements express this theme:

This is one of the most significant components of the educational process. The development and nurturing of moral resilience and Moral Courage creates a thinking, intelligent, and containing society. The individuals who constitute this society feel confident about their worldviews. Educating for moral resilience has the power to prevent feelings of cultural inferiority. It empowers the individual's world of values and makes it possible to conduct interpersonal discussions on issues of principle, while feeling safe (Anna).

Moral resilience and moral courage are the development and strengthening of a system that enables students to maintain positive values, within a reality rife with difficulties. That is, it provides ways to cope with situations characterised by a dissonance between what actually happens in reality, be it on the individual or on a broader social level, and the values in which we believe (Don).

Moral resilience is the feeling acquired when teachers feel free to inculcate values to students, both directly and indirectly, [while] receiving support from the framework in which they teach. [Moral resilience is] the ability to remain loyal to one's values, without depending on the opinions of either other team members or the Ministry of Education, etc. (Homi). 
The extent of the person's ethical teaching performance helps cope with difficulties This resilience where I'm putting my foot, I'm sure the important values and not giving up even if there is a situation of pressure from those around me all the teaching, namely pressure can be activated by parents, staff with him I worker or manager (homi).

Moral resilience of an individual is the ability to cope with situations using the values that he or she believes in, even when parents disapprove. [It means] maintaining your moral ground, even when it is not clear whether the management will support you on this particular issue. Still, you hope to receive support from the system on the matter at hand (Shir).

To summarize this theme, most of the responses indicated that that the process of exercising moral resilience or moral courage always takes place within the confines of some kind of framework, whether the framework is perceived as operating on the micro level (the individual), the meso-level (the school), or the macro level (the community).

\section{Theme 2: The Linkage between Moral Courage and Moral Resilience}

Three major themes emerged in trainees' conceptualizations of the notion of moral resilience and moral courage: (1) The Social-Educational Framework as a Protective Environment (2) The linkage between the two terms -- moral resilience and moral courage; (3) the terms as buzzwords.

(a) The pattern that consists of the logical connection based on a relationship of cause and effect.

Moral resilience is used to define moral courage and sometimes-moral courage is used to explain moral resilience. Sometimes one is the starting point and sometimes the other is the starting point.

Moral resilience is related to moral courage; there is no endurance without courage. If one has the courage to stand up for oneself, then the resilience values will be reflected in one's way of acting, teaching, or in one's ideological attitude. Teachers who have no moral courage and do not know how to resent their perceptions while maintaining their ideals and principles cannot inspire mental strength.

Sometimes moral resilience will cause us to use moral courage, to be daring and unafraid, empowering us to act the way we chose. Moral courage is to adhere to the values we believe in without any doubt, not to be afraid of talking about morals as we see them, so a person with moral resilience necessarily has moral courage: the strength to adhere to one's beliefs ... . Someone who has no moral courage and does not maintain his or her stance regarding ideals and principles is unable to inspire mental strength or moral resilience in others. The two things are intertwined. A person who is steady and strong has the ability to 
withstand criticism and overcome fear, maintaining the beliefs and morals that guide him (Dani)

Moral courage rests and is based on moral strength; moreover, moral courage is the tool through which moral fortitude is maintained. Values are based on morality, and morality is derived from the values. These two concepts are difficult to separate. In addition, morally courageous teachers can teach morality through the strong values they espouse them (Gabi).

Moral courage is to stand boldly and bravely in front of "others," adhering to one's principles rather than submitting to external dictates, and strength means adherence to the values (Hen).

Creating a foundation of moral resilience renders courageous moral actions superfluous. Instead, the establishment of a world of values is already rooted in courage.

Moral courage is the ability to do, the ability to act, the same as moral resilience. Not to be dragged into reactions and to maintain a neutral stance for learning. For example, there is a connection between moral courage and moral resilience when people argue their point of view or ideology, but still do not hesitate to accept different points of view (Gil).

I think that moral courage is the opposite of moral resilience. Moral courage implies a desire to touch and influence others and create learning, and resilience means protecting ones values to the point of being immune to the influence of others (Ron).

You might be morally resilient, but not have the moral courage to take action, because moral courage is tested in the act. As a teacher, you would not have the courage to act on your beliefs. (Bety)

\section{(b) The pattern of overlap.}

Moral courage helps maintain one's moral resilience and uniqueness, although it can lead to feelings of alienation, highlighting differences, and provoking reactions from the external environment. [Moral resilience] helps maintain moral courage and moral fortitude, to keep your uniqueness even though it can cause alienation or external reactions (Yonit).

When teachers insist and adhere to their values and have the courage to maintain their position, they demonstrate their prioritized values and sense of morality, issues on which they refuse to compromise. In addition, there is a qualitative correlation between the two terms: the greater one's moral resilience is, the more one is morally courageous. (Ruth).

In addition, there is also a connection between qualities: strong moral resilience is related to strong values, and then moral courage is reflected in the way one acts or teaches. 
Strong values is the sense one gets when teachers feel they can instill values in their students directly and indirectly, and receive support from the educational framework to which they belong. Teacher must be sure that their views and values are expressed in a way that would not negate the students' values or affect them adversely. It is not always easy to resist the pressure of the environment and its impact on our actions. Sometimes teachers need to position themselves against the mainstream and to demonstrate that their values are not those of their surrounding environment.[It is important] to demonstrate faith in our values and to act on them, even if this behavior arouses antagonism towards us and causes others to reject us. (Nili).

Having moral resilience means a willingness to dare and not to forego an opportunity to educate towards values, despite the awareness that such acts might exact a heavy penalty. Someone who can do that is a moral person with a strong personality that will only become stronger.

\section{The relation between moral courage and moral resilience is based on a relationship of cause and effect.}

Moral resilience is perceived by some of the participants as the motivation to be morally courageous, while others use the concept of moral courage to explain moral resilience. Either term may initiate a cycle, according to which the greater one's moral resilience is, the more one is likely to demonstrate moral courage.

Moral resilience is related to moral courage; there is no endurance without courage. If one has the courage to stand up for one's convictions, then one's resilient values will be reflected in the way one acts and teaches, or in one's ideological attitude. Teachers who have moral courage but do not know how to express their views, their ideals, or their principles cannot inspire mental strength and empower others (Mori).

Sometimes moral resilience will cause us to use moral courage, to be daring and unafraid, empowering us to act the way we choose. Moral courage is adhering to the values that we believe in, without any hesitation. We can talk without any fear about morals as we see them; so a person with moral resilience necessarily has moral courage: the strength to adhere to one's beliefs.... one who has no moral courage and does not maintain his or her stance regarding ideals and principles is unable to inspire mental strength or moral resilience in others. The two are intertwined: A person who is consistently strong has the ability to withstand criticism and overcome fear, maintaining the beliefs and morals that guide him (Dani)

Moral courage relays and is based on moral strength; moreover, moral courage is the tool through which moral fortitude is maintained. Values are based on morality, and morality is derived from values. These two concepts are difficult 
to separate. In addition, morally courageous teachers can teach morality through the strong values they believe in (Gabi).

Moral courage is to stand boldly and bravely in front of "others," adhering to one's principles, rather than submitting to external dictates: strength means adherence to values (Hen).

Creating a foundation of moral resilience renders courageous moral actions superfluous. Instead, the establishment of a world of values is already rooted in courage (Mor).

Moral courage is the ability to do, the ability to act, the same as moral resilience. Not to be dragged into reactions, and to maintain a neutral stance for learning. For example, there is a connection between moral courage and moral resilience when people argue their point of view or ideology, but still do not hesitate to accept different points of view (Gil).

Moral resilience or moral courage (sometimes the moral courage leads to action and sometimes you act and become moral because of your moral resilience) means coping with situations, in which one chooses not to give in or cut corners, issues related to the moral principles and values that one upholds, even if the education system demands otherwise.... (Gila).

\section{Theme 3: A Buzzword}

A small group of responders (7\%) claimed that the concept of resilience or moral courage is no more than a buzzword. According to their statements, it appears that they view this concept as fashionable, a term that does not convey any real content. "This concept belongs in the graveyard of pedagogical -isms that were defined a long time ago and are now only presented in a slightly different guise, given the need to show off the use of new semantic definitions". "The foundations of educational theory are ancient and do not change; therefore, anything done in the present is only a new presentation of the same ideas in a shiny new coat of paint, without the introduction of any substantial change. Consequently, the term moral resilience is misleading and creates expectations that cannot be fulfilled."

\section{Discussion}

The current study aims to present the characteristics of moral resilience and moral courage according to the perceptions of students in teacher-training colleges. The findings, which are based on participants' responses, suggest that teacher trainees' perception of the notion of moral resilience corresponds to the model of personal resilience presented by Taplin (2011). This model highlights the connection between the factors of personal characteristics, self-efficacy (Bandura, 1997), and individual resistance (Newman, 2002), and the individual's web of social affiliations. Participants emphasized that for them; personal characteristics are meaningful and are responsible for future actions in a social framework. Based on their answers, it becomes clear that the participants understand that the fabric of their personal characteristics cannot be considered a mere theoretical essence that leads to the development 
of beliefs or an educational worldview. Rather, in their view, these beliefs should be developed into an educational ideology that is expressed in the field, through curricular functions, particularly through covert functions such as modeling, functions that serve to inculcate values in a manner unrelated to time, place, or approach. Similarly, this can be done by forming reciprocal relationships among all who participate in the educational process, while preserving a normative framework, which dictates the rules. The teacher trainees spoke from an idealistic point of view, conveying perhaps a slight naiveté, because they are not actually yet working from within the educational system and have not experiences the related difficulties. Nevertheless, they recognize that there must be a support mechanism and they speaking of an organizational framework that provides the conditions for creating balanced system within which they will be able to function.

Participants' responses provide an indication of the necessary qualities that a teacher must have to be morally resilient. Such a teacher must act consistently, demonstrate stability, be a capable decision maker, adhere to a comprehensive set of morals and values, and occasionally exhibit moral courage. They also noted that the environment plays an important role, and that teachers should be able to function within the regular framework of activities and factors that are typically involved in the educational endeavor. In this, their perceptions were reminiscent of those stated by Gu and Day (2007).

Alongside the participants who attempted to define the concept, a small marginal group claimed, "There is nothing new under the sun". It became apparent that according to the perceptions of this group, underlying the concept of moral resilience and moral courage are the principle that, inherent in all actions is a basic educational ethos, the foundations of which have long since been formed and taken root in one's conscious. Hence, the role of the teacher is to continue to demonstrate the principle of moral resilience in accordance with the notions that have already been etched into their educational consciousness.

The attempt to focus on a common denominator among the majority of the opinions and statements provided by the respondents led to the understanding that there was no single, shared, clear and comprehensive definition of the concept. The reason for this may be that the term is not an integral part of the Israeli educational discourse and consequently there is little awareness of it among the trainees. Moreover, the concept of resilience is referred to in the media in a variety of contexts which are not necessarily related to either morals or teaching. Therefore, when the term was introduced in an educational context it was interpreted on a personal level. This suggests that there is room to hone people's understanding of the concept in the educational context. It is important to empower those who use( ( of the term and to find ways to integrate it in the teacher-training process, so that teachers are exposed to it before they begin teaching in the field (Gu \& Day, 2013).

Ethical or moral conflicts and debates are an integral part of any society. Some suggestions about content and learning experiences in teacher education have been made (Castro, Kelly, \& Shih, 2010), but studies of teacher resilience at the pre-service level are limited (Mansfield, Beltman, Price, \& McConney, 2012). While it is acknowledged that the resources teachers 
use to enable resilience are influenced by life experience and career stage, there seems to be agreement that teacher education may play a critical role in the resilience process (author, 2015). Gu (2014) noted that, efforts to increase the quality of teaching and raise standards of learning and achievement for all pupils must focus on efforts to build, sustain and renew teacher resilience, and that these efforts must take place in initial teacher training. In the context of the teaching profession, resilience may be conceptualized as a capacity, a process and as an outcome.

Based on the responses of teacher trainees, it is evident that they believe that the assimilation of these concepts is achieved by imitating the actions modelled by the teacher. Consideration should also be given to the degree to which preservice educators already possess and can model some of the skills suggested or have the capacity to provide resources needed by their students (Mansfield, Beltman, Broadley, \& Weatherby-Fell, (2016). In order to instill moral resilience and moral courage in teacher trainees, they need to receive the appropriate tools during the training process. Such tools would enable trainees to perform their educational responsibilities, identify educational needs, and most importantly to construct an appropriate educational response as the need arises, using content that is timely, relevant, and can serve as a basis for future learning and education.

Undoubtedly, by developing personal moral resilience and personal moral courage, teachers-in-training will have the ability later on in their careers to exert their personal influence on the educational endeavor. Where moral culture and moral discourse is exist and integrated into informal work routines, such discourse can lead to the development of shared beliefs and perceptions.

\section{References}

American Psychiatric Association. (2009). Diagnostic and statistical manual of mental disorders (4th ed.), Author, Washington, DC.

Bandura, A. (1997). Self-efficacy - The exercise of control, New York: Freeman, New York.

Barandes, A., \& Isaschar, R. (Eds.). (2013). Educating for values in a changing world. A collection of position papers requisitioned by the Committee for Groundbreaking Research. A proposal for the reorganization of schooling, Jerusalem: The Initiative for Applied Research in Education (in Hebrew).

Author (2010). The ideological dilemma in teaching literature process-moral conflicts in a democratic and nationally diverse society: An Israeli teacher case study. Current Issues in Education, 13(3), 79-93.

Author (2013). Israeli teachers' definitions of morally courageous behavior in education. Journal of Education and Learning, 2 (1), 84-93.

Author (2015),"Israeli teacher trainees' perceptions of the term moral resilience "journal for Multicultural Education, Vol. 9, Issue 3 pp. 193 - 206. 
Berggren, K. (2006, April 26). The link between spirituality and resilience in children. National Catholic Reporter, p. 16.

Bleich, A. (2007, April). Individual resilience, societal resilience. Natal Newsletter, 9. Retrieved from http://www.natal.org.il/English/?CategoryID=257\&ArticleID=254.

Buzaglow, A. (2010). Teacher training for moral education in a state college in Israel. $\mathrm{PhD}$ Dissertation, Bar Ilan University Ramat Gan, Israel (in Hebrew).

Castro, A. J., Kelly, J., \& Shih, M. (2010). Resilience strategies for new teachers in high-needs areas. Teaching and Teacher Education, 26(3), 622- 629. http://x.doi.org/10.1016/j.tate.2009.09.010.

Duska, R. (2013). Integrity and moral courage, Journal of Financial Service Professionals, 67(1), 20-22.

Ediger, M. (2013). The teacher and students in the Social Studies. College Student Journal, $47(4), 649-651$.

Edwards, A. (2011, January). Agency, motives and practices. Paper presented at the ESRC seminar series on A Multi-Disciplinary Inquiry into the Nature and Forms of Workplace Resilience: Teacher Retention and Effectiveness in Times of Change, University of Nottingham.

Gal, R. (2003, December), National-social resilience. National Security Council. Publication of the Office of the Prime Minister. Retrieved from http://www. herzliyaconference.org/?ArticleID=955\&CategoryID=170.

Goetz, J. P., \& Le Compte, M. D. (1984). Qualitative research in social studies education. In James P. Shaver (Ed.), Handbook of research on social studies teaching and learning, A project of the National Council for the Social Studies (pp. 56-67). New York: MacMillan.

Graff, G. (1994). Teaching the conflict: Gerald Graff Curricular reform, and the Culture War. (ed.) w.E. Cain. Garland Publication.N.y. \& London.

$\mathrm{Gu}, \mathrm{Q}$. (2014). The role of relational resilience in teachers' career-long commitment and effectiveness. Teachers and Teaching: Theory and Practice, 20(5), 502 - 529. http://dx.doi.org/10.1080/13540602.2014.937961.

Gu, Q., \& Day, C. (2007). Teachers' resilience: A necessary condition for effectiveness, teaching. Oxford Review of Education, 33(4), 423-443.

Gu, Q., \& Day, C. (2013). Challenges to teacher resilience: Conditions count. British Educational Research Journal, 39(1), 22-44.

Guba, E. G., \& Lincoln, Y. S. (1989). Competing paradigms in qualitative research. In N. K. Denzin \& Y. S. Lincoln (Eds.), Handbook of qualitative research (pp. 105-117). Thousand Oaks, CA: Sage. 
Herrman, H., Stewart, D. E., Diaz-Granados, N., Berger E. L., Jackson, B., \& and Yuen, T. (2011). What is resilience? The Canadian Journal of Psychiatry, 56(5), 258-265.

Katriel, T. (1999). Keywords: Culture and communication patterns in Israel. Haifa: University of Haifa \& Zmora-Bitan (in Hebrew). Kidder, R. M. (2005). Moral courage: Ethics in action. New York: Harper Paperbacks.

Kidder, R. M. (2005). Moral courage: Ethics in action. New York: Harper Paperbacks.

Killian, B. (2004). Risk and resilience. In R. Pharoah (Ed.), A generation at risk? HIV/AIDS, vulnerable children and security in Southern Africa (pp.33-63). South African Institute for Security Studies. Retrieved from http://www.iss.org.za/uploads/ 109CHAP3.PDF

Klaassen, C. (2007). The moral role of teachers investigated. What did we learn? Paper presented at the 2007 annual convention of the American Educational Research Association. Chicago.

Klaassen, C. (2010). Teachers' view and the need for moral courage. In C. Klaassen, \& N. Maslovaty (Eds.), Moral courage and the normative professionalism of teachers (pp.13-26). Rotterdam: Sense Publishers.

Klaassen, C., \& Maslovaty, N. (2010). Teachers and normative perspectives in education: An introduction. In C. Klaassen, \& N. Maslovaty (Eds.), Moral courage and the normative professionalism of teachers (pp.1-12). Rotterdam: Sense Publishers.

Lachman, V. D. (2007). Moral courage in action: Case studies. MEDSURG Nursing, 16(4), $275-277$.

Mansfield, C. F., Beltman, S., Price, A., \& McConney, A. (2012). "Don't sweat the small stuff": Understanding teacher resilience at the chalkface. Teaching and Teacher Education, 28, 357e367. http://dx.doi.org/10.1016/j.tate.2011.11.001.

Mansfield, C. F., Beltman, S., Broadley, T., \& Weatherby-Fell, N. (2016). Building resilience in teacher education: An evidence informed framework. Teaching and Teacher Education, 54, 77-87.

Newman, T. (2002). Promoting resilience: A review of effective strategies for childcare services -- Prepared for the Centre for Evidence-Based Social Services, University of Exeter. Discurso, 7, 353-371.

Ofer, A., Rix, R., \& Harel, A. (2008). The moral resilience of a military unit. Final project, submitted to the Mandel Leadership Institute, Jerusalem.

Ogman, D. (2012). How to cope with stress? Training for mental resilience. Retrieved from http://dalya.webege.com/wordpress/?page_id=24 (in Hebrew).

Peled, D. (Ed.). (2004). the social planning committee - the communal resilience team. Jerusalem: The Parliamentary National Security Commission (in Hebrew). 
Schechter, M., \& Iram, Y. (2002). Values and educating about values. In N. Masolveti, \& Y. Iram (Eds.), Educating about values in the context of teaching (pp. 11-29). Tel Aviv: Ramot.

Sovran, T. (2013). Relational semantics and the anatomy of abstraction. New York: Routledge.

Spradley, J. P. (1979). The ethnographic interview. New York: Holt, Rinehart \& Winston.

Taplin, M. (2011). Silent sitting: A cross-curricular tool to promote resilience. International Journal of Children's Spirituality, 16(2), 75-96.

Weber, R. P. (1985). Basic content analysis. Beverly Hills, CA: Sage.

Yizhar, S. (1990). Two controversies: On education and on literature. Tel Aviv: Zmora Bitan (in Hebrew).

\section{Copyright Disclaimer}

Copyright reserved by the author(s).

This article is an open-access article distributed under the terms and conditions of the Creative Commons Attribution license (http://creativecommons.org/licenses/by/3.0/). 